\title{
Dimensional analysis and stage-discharge relationship for weirs: a review
}

\author{
Mohammad Bijankhan, ${ }^{1}$ Vito Ferro ${ }^{2}$ \\ ${ }^{1}$ Department of Water Engineering, Imam Khomeini International University, Qazvin, Iran; \\ ${ }^{2}$ Department of Agricultural and Forestry Sciences, University of Palermo, Italy
}

\begin{abstract}
Deducing the weir flow stage-discharge relationship is a classical hydraulic problem. In this regard Buckingham's theorem of dimensional analysis can be used to find simple and accurate formulas to obtain the rating curves of different weir types. At first, in this review paper the rectangular weir that is a very common hydraulic structure is studied. It is indicated that the crest shape, approach channel width, obliquity (angle between the weir crest and the direction normal to the flow motion) and vertical inclination (pivot weir) are the key-parameters affecting the flow over the rectangular weirs. The flow over the triangular, labyrinth, parabolic, circular, elliptical, and W-weirs are also studied using dimensional analysis and incomplete self-similarity concept. For all mentioned weirs the stage-discharge relationships are presented and the application limits are discussed. The results of this paper can be used and implemented by the irrigation and drainage network designers to simplify the procedure of weir design.
\end{abstract}

\section{Introduction}

Weirs are elevated barriers generally located normal to the main flow direction for forcing the fluid to rise above the obstruction to flow through a regular-shaped opening (Bautista-Capetillo et al., 2014). Weirs are usually used in irrigation networks as water measurement structures or controlling the upstream water depth.

Correspondence: Vito Ferro, Department of Agricultural and Forestry Sciences, University of Palermo, viale delle Scienze, 90128 Palermo, Italy.

Tel. + 39.091.23897068.

E-mail: vito.ferro@unipa.it

Key words: Rectangular weir; triangular weir; labyrinth weir; parabolic weir; circular weir; elliptical weir; W-weirs, Buckingham's theorem; incomplete self-similarity.

Received for publication: 21 June 2016.

Accepted for publication: 17 September 2016.

(C) Copyright M. Bijankhan and V. Ferro, 2017

Licensee PAGEPress, Italy

Journal of Agricultural Engineering 2017; XLVIII:575

doi:10.4081/jae.2017.575

This article is distributed under the terms of the Creative Commons Attribution Noncommercial License (by-nc 4.0) which permits any noncommercial use, distribution, and reproduction in any medium, provided the original author(s) and source are credited.
They are also constructed to convey the excess water over the dams due to the floods. Even if weirs have the same general definition, the application and characteristics depend on the specific weir type (Borghei et al., 2003)

There are different kinds of weirs which are classified based on either the cross sectional shape, plan view, or the crest length. The rectangular, triangular, parabolic, elliptic and circular weirs are different types of the cross sectional shapes. A sharp-crested rectangular weir consists of a vertical thin, generally metal, plate that is placed normally to the flow direction. A sharp-crested inclined weir, named pivot weir, is a plate angled to the bottom of the channel (Nikou et al., 2016).

A labyrinth weir is used to increase the discharge capacity compared to a linear weir installed in a channel with a specific width. The advantage of the labyrinth weir over the linear one is the longer crest length. Different shape configurations such as triangular, trapezoidal, and rectangular have been used to fold the weir in plan-view thereby a longer crest length than a linear weir is obtained. The performance of a labyrinth weir in connection with some influencing factors including crest length, plan shape, and number of cycles (that is repeated modules), has been studied widely and design guide lines were proposed (e.g., Horton, 1907; Taylor, 1968; Hay and Taylor, 1970; Darvas, 1971; Tullis et al., 1995). Weirs can be classified according to the length of the crest into broad-crested and short-crested weirs based on whether or not a region of parallel flow exists on the weir (Azimi and Rajaratnam, 2009). If the crest length $L_{c}$ and the flow head are such that the flow separates and does not attach to the weir before the flow leaves the weir, then the finite crest length weir works as a sharp-crested one (Ferro, 2013). According to $h / L_{c}$ ratio, where $h$ is the water depth measured from the reference horizontal plane localised at the weir crest, the weirs of a finite crest length are categorised into four groups (Hager and Schwalt, 1994; Azimi et al., 2013a). That is long-crested weir $\left(0<h / L_{c} \leq 0.1\right)$, broad-crested weir $\left(0.1<h / L_{c} \leq 0.4\right)$, short-crested weir $\left(0.4<h / L_{c} \leq 2\right)$, and sharp crested weir $\left(h / L_{c}>2\right)$. When weirs are used for measuring discharge the structure is characterised by a relation between the discharge and the upstream water level, named stage-discharge relationship, which depends primarily on the shape and dimensions of the structure. The most well-known stage-discharge formula is obtained by integrating the velocity profiles over the weir crest (Bos, 1989).

These structures were studied using classical physics and experimental analysis to understand the characteristics of flow and to determine the discharge coefficient $C_{d}$. This coefficient represents the effects not considered in the derivations of the equations used for estimating discharge from flow depth. Such effects include viscosity, surface tension, velocity distribution in the approach channel, and streamline curvature due to weir contraction (Aydin et al., 2011). For a rectangular normal sharp-crested weir, the well-known stage-discharge relationship is derived from energy considerations and the discharge $Q$ of the free flow over the weir is given by (Herschy, 1999, Aydin et al., 2002; Aydin et 
al., 2011; Gharahjeh et al., 2015):

$Q=\frac{2}{3} C_{d} L_{c} \sqrt{2 g} h^{3 / 2}$

in which $h$ is the water depth measured from the reference level (horizontal plane localised at an elevation equal to the weir height $p$ ) and at a distance from the weir equal to $2-3 h$, and $g$ is acceleration due to gravity.

Dimensional analysis can also be used to investigate the flow over the weirs. When the dimensional analysis is applied for studying a physical process the starting point of the investigation is only to establish the quantities, which characterise the phenomenon being studied (Barenblatt, 1987). Furthermore Barenblatt (1987) explicitly stated that if the explicit mathematical formulation of the problem is unknown, the governing parameters are chosen on the basis of a qualitative model of the phenomenon, which each investigator constructs using his/her own experience, intuition; as well as an analysis of previous studies. Barenblatt (1987) also underlined that: In some cases, it turns out to be convenient to choose new similarity parameters - products of powers of the similarity parameters obtained in the previous step. In other words, Barenblatt (1987) suggested to combine the original dimensionless groups to obtain new similarity parameters $\Pi$.

The stage-discharge relationship for a rectangular weir having a weir width $L_{c}$ equal to the channel width, $B$, and a weir height $p$ can be expressed by the following functional relationship:

$$
\Phi(h, Q, B, p, g, \mu, \rho, \sigma)=0
$$

where $\Phi$ is a functional symbol, $\mu$ is the water viscosity, $\rho$ is the water density and $\sigma$ is the water surface tension.

Using the $\Pi$-theorem of dimensional analysis the following functional relationship can be deduced (Ferro, 2012):

$$
f\left(\frac{k_{s}}{p}, \frac{h}{p}, \operatorname{Re}, W e\right)=0
$$

in which $k_{s}$ is the critical depth defined by $k_{s}=Q^{2 / 3} /\left(B^{2 / 3} g^{1 / 3}\right), R e$ and $W e$ are the Reynolds and Weber numbers, respectively.

Except for very low values of the water head, $h$, measured over the weir, the effects of the Reynolds number and the Weber number (Rao and Shukla, 1971; Ranga Raju and Asawa, 1977; De Martino and Ragone, 1984; Sargison, 1972) have been found to be negligible. Consequently, neglecting the effects of the Reynolds and Weber numbers Eq. (3) yields:

$$
\frac{k_{s}}{p}=\psi\left(\frac{h}{p}\right)
$$

where $\psi$ is a functional symbol.

The mathematical shape of the functional relationship (4) can be found using the incomplete self-similarity theory (Barenblatt, 1979, 1987).

A phenomenon is defined as self-similar in a given dimensionless group $\Pi_{n}$ when the functional relationship $\Pi_{n}=\varphi_{1}\left(\Pi_{2}, \Pi_{3}\right.$, ..........., $\Pi_{n}$ ), is independent of $\Pi_{n}$. When $\Pi_{n} \rightarrow 0$ or $\Pi_{n} \rightarrow \infty$ and the corresponding limits of the function $\varphi_{1}$ equal to 0 or $\infty$, then the incomplete self-similarity (ISS) in the parameter $\Pi_{n}$ would occur. For such a case the function $\varphi_{1}$ can be written as (Barenblatt, 1979, 1987):

$$
\Pi_{1}=\Pi_{n}^{\varepsilon} \varphi_{2}\left(\Pi_{2}, \Pi_{3}, \ldots \ldots . ., \Pi_{n-1}\right)
$$

in which $\varphi_{2}$ is a functional symbol and $\varepsilon$ is a numerical constant.

Generally for the weir flow, when $h / p \rightarrow 0$ then $k_{s} / p \rightarrow 0$ and when $h / p \rightarrow \infty$ then $k_{s} / p \rightarrow \infty$, consequently the ISS condition occurs. Therefore Eq. (4) takes the following form:

$$
\frac{k_{s}}{p}=a\left(\frac{h}{p}\right)^{m}
$$

where $a$ and $m$ are numerical constants that should be determined experimentally.

On the other hand, rearranging Eq. (1) the following expression is obtained:

$$
\frac{Q^{2 / 3}}{b^{2 / 3} g^{1 / 3}}=\left(\frac{8 C_{d}^{2}}{9}\right)^{1 / 3}
$$

Setting

$$
k_{s}=\frac{Q^{2 / 3}}{b^{2 / 3} g^{1 / 3}}
$$

$$
a=\left(\frac{8 C_{d}^{2}}{9}\right)^{1 / 3}
$$

Eq. (1) can be rewritten:

$$
\frac{k_{s}}{p}=a\left(\frac{h}{p}\right)
$$

Theoretically Eq. (6) which is obtained based by the dimensional analysis and the self-similarity theory reduces to Eq. (9) by considering $m=1$. This theoretical hypothesis requires however to be analysed for different kinds of weirs. This paper, as the state of the art, presents a background of the stage-discharge relationship deduced by applying dimensional analysis and self-similarity theory for different types of the weirs. Rectangular weirs including Bazin, oblique, broad crested weir, finite crest length, triangular weirs (Thomson, triangular in plans), W-weirs, parabolic, elliptical and circular weirs are considered. The accuracy of the proposed formulas and their application ranges are also discussed. The results of this paper can be used for the open channel designers.

\section{Rectangular weirs}

Crest shape, approach channel width, obliquity (angle between the weir crest and the direction normal to the flow motion) and vertical inclination (pivot weir) are the key parameters affecting the flow over the rectangular weirs (Bagheri and Heidarpour, 2010). In this section the capability of using the Buckingham's theorem with the incomplete-self similarity theory will be discussed to study the hydraulic characteristics of the weir flow problem. 


\section{Crest shape effect on the head-discharge relation- ship}

As previously stated, finite crested weirs are classified into long-, broad-, short-, and sharp-crested based on the ratio of the upstream head to the weir crest length. Azimi et al. (2013a) indicated that the crest length should also be incorporated in the functional relationship proposed by Ferro (2012). Bijankhan et al. (2014), for the weirs of finite crest length of $L_{c}$ (Figure 1A), indicated that the stage discharge relationship could be expressed by the following functional relationship:

$\Phi\left(Q, h, p, B, L_{c}, g, \mu, \rho, \sigma\right)=0$

where $\Phi$ is a functional symbol.

Using $p, g$ and $\rho$ as dimensional independent variables, the following dimensionless groups can be obtained:

$\Pi_{1}=p^{-1} h$

$\Pi_{2}=\frac{Q}{g^{1 / 2} p^{5 / 2}}$

$\Pi_{3}=\frac{B}{p}$

$\Pi_{4}=\frac{L_{c}}{p}$

$\Pi_{5}=\frac{\mu}{p^{3 / 2} g^{1 / 2} \rho}$

$\Pi_{6}=\frac{\sigma}{p^{2} g \rho}$

Combining the groups $\Pi_{1}$ and $\Pi_{4}$ yields:

$\Pi_{1,4}=\frac{\Pi_{1}}{\Pi_{4}}=\frac{h}{p} \frac{p}{L_{c}}=\frac{h}{L_{c}}$

Taking into account Eqs. (12) and (13), the following dimensionless group is obtained:

$\Pi_{2,3}=\frac{\Pi_{2}^{2 / 3}}{\Pi_{3}^{2 / 3}}=\frac{Q^{2 / 3}}{g^{1 / 3} p^{5 / 3}} \frac{p^{2 / 3}}{B^{2 / 3}}=\frac{k_{s}}{p}$

Combining Eqs. (12), (13) and (15), the following dimensionless group is obtained:

$\Pi_{5,3,2}=\frac{\Pi_{2}}{\Pi_{5} \Pi_{3}}=\frac{Q}{g^{1 / 2} p^{5 / 2}} \frac{p^{3 / 2} g^{1 / 2} \rho}{\mu} \frac{p}{B}=\frac{\rho Q}{\mu B}=\operatorname{Re}$

in which $R e$ is the Reynolds number.

Considering the definitions of $\Pi_{1}$ and $\Pi_{6}$, the following dimensionless group is obtained:
$\Pi_{1,6}=\frac{\Pi_{1}^{2}}{\Pi_{6}}=\frac{h^{2}}{p^{2}} \frac{p^{2} g \rho}{\sigma}=\frac{\rho g h^{2}}{\sigma}=W e$

in which $W e$ is the Weber number.

According to the Buckingham's theorem it is possible also to combine the dimensionless variables commonly used in hydraulics, therefore, the functional relationship Eq. (10) can be rewritten in the following form:

$\Pi_{1,4}=f\left(\Pi_{2,3}, \Pi_{4}, \Pi_{5,3,2}, \Pi_{1,6}\right)$

where $f$ is a functional symbol.

Introducing the results into Eq. (21), the functional relationship can be rewritten in the following form:

$\frac{h}{L_{c}}=b\left(\frac{k_{s}}{p}\right)^{m}$

Neglecting the effects of the Reynolds number, $R e$, and the Weber number, Eq. (22) becomes:

$\frac{h}{L_{c}}=\omega\left(\frac{k_{s}}{p}, \frac{L_{c}}{p}\right)$

where $\omega$ is a functional symbol.

The mathematical shape of the functional relationship, Eq. (23), can be deduced using the incomplete self-similarity theory (Barenblatt, 1979; 1987). For a given $L_{c} / p$ value, when $k_{s} / p \rightarrow 0$ then and $h / L_{c} \rightarrow 0$ when $k_{s} / p \rightarrow \infty$ then $h / L_{c} \rightarrow \infty$, and consequently the ISS occurs. Therefore, for a given $L_{d} / p$ value Eq. (23) would be:

$$
\frac{h}{L_{c}}=b\left(\frac{k_{s}}{p}\right)^{m}
$$

where the coefficient $b$ is a function of $L_{c} / p$ that should be obtained experimentally.

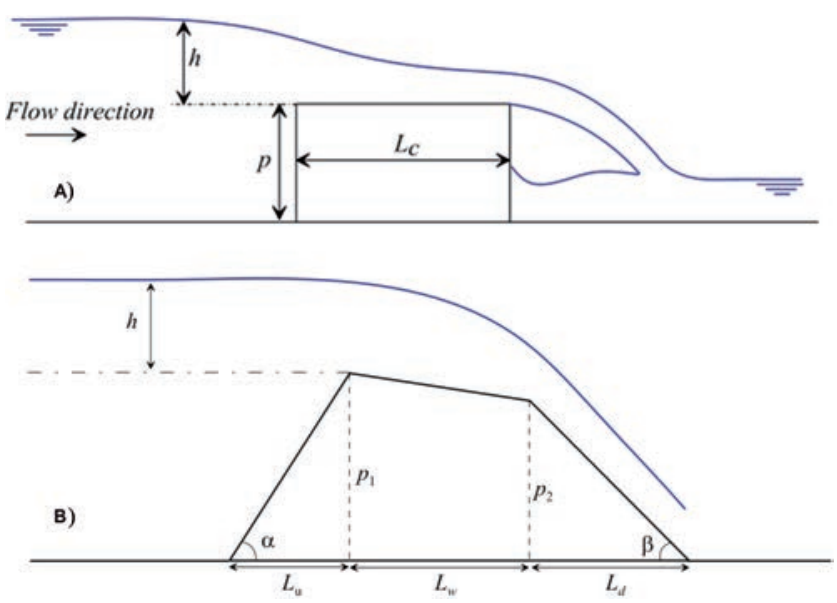

Figure 1. General sketch of the finite crested weir (A) and of the complex-shape weir (B). 
Eq. (24) was then calibrated by the experimental data performed by Bijankhan et al. (2015) and the following expression was proposed for the coefficient $b$ :

$b=1.4915\left(\frac{L_{c}}{p}\right)^{-0.962}$

Eqs. (24) and (25) represents the stage discharge relationship of the finite crested weirs. The applicability range of these equations is limited to the experimental data listed in Table 1.

Comparing the head-discharge relationship (Eqs. 24 and 25) with the experimental data it was revealed that $69.4 \%$ of the data points can be predicted by the relative error of less than $\pm 5 \%$. Also the relative error of $26.5 \%$ and $4.1 \%$ of the data points fall within the ranges of $5 \%-10 \%$ and greater than $10 \%$ respectively.

Employing the broad-crested weir equation and the available experimental data, Azimi et al. (2013b) developed stage-discharge formulations for weirs of finite crest length having upstream and/or downstream ramps. Accordingly, the crest shape would affect also the flow over rectangular weirs (Azimi et al., 2013b; Bijankhan et al., 2015). Di Stefano et al. (2016a) present a new definition of the crest shape called complex-shape weir, as indicated in Figure 1B. This definition of the crest shape covers a large variety of the crest shapes, which is very helpful to develop a general head-discharge weir formula. According to this figure the following crest shapes can be distinguished (Di Stefano et al., 2016a): i) finite crested weirs (FCW), including long-, broad-, short- and sharp-crested weirs, for which $p_{1}=p_{2}, \alpha=\beta=\pi / 2, L_{u}=L_{d}=0$; ii) broad crested weir with a positive crest slope (BCW-PS), $p_{1}>p_{2}, \alpha$ $=\beta=\pi / 2, L_{u}=L_{d}=0$; iii) broad crested weir with a negative crest slope (BCW-NS), $p_{1}<p_{2}, \alpha=\beta=\pi / 2, L_{u}=L_{d}=0$; iv) broad crested weir with an upstream crest ramp (BCW-UR), $p_{1}=p_{2}, \beta=\pi / 2$, $\left.0<\alpha<\pi / 2, L_{d}=0, L_{u}>0 ; \mathrm{v}\right)$ broad crested weir with a downstream crest $\operatorname{ramp}(\mathrm{BCW}-\mathrm{DR}), p_{1}=p_{2}, \alpha=\pi / 2,0<\beta<\pi / 2, L_{u}=0, L_{d}>0$; vi) broad crested weir with both upstream and downstream crest ramp (BCW-UDR), $p_{1}=p_{2}, 0<\alpha<\pi / 2,0<\beta<\pi / 2, L_{u}>0, L_{d}>0$; vii) triangular weir with an upstream ramp (TW-UR), $p_{1}=p_{2}, 0<\alpha<\pi / 2, \beta=\pi / 2$, $L_{w}=0.002 \mathrm{~m}, L_{d}=0, L_{u}>0$; viii) triangular weir with a downstream ramp (TW-DR), $p_{1}=p_{2}, \alpha=\pi / 2,0<\beta<\pi / 2, L_{w}=0.002 m, L_{u}=0, L_{d}>0$; ix) triangular weir with an upstream and downstream ramp (TWUDR), $p_{1}=p_{2}, 0<\alpha<\pi / 2,0<\beta<\pi / 2, L_{w}=0.002 m, L_{d}>0, L_{u}>0$.

Considering that $L_{u}=p_{1} / \tan (\alpha)$ and $L_{d}=p_{2} / \tan (\beta)$, the general definition of the stage discharge relationship can be expressed by the following functional relationship:

$$
\Phi\left(h, Q, B, L_{u}, L_{w}, L_{d}, p_{1}, p_{2}, g, \mu, \rho, \sigma\right)
$$

where $\Phi$ is a functional symbol.

Using the Buckingham's theorem and incomplete self-similarity theory as described before for the finite crested weirs, Di Stefano et al. (2016a) developed the following generalised nondimensional stage-discharge relationship for the complex-shape weirs:

$$
\frac{h}{p_{1}}=b\left(\frac{k_{s}}{p_{1}}\right)^{m}\left(\frac{L_{w}}{p_{1}}\right)^{n}\left(1+\frac{L_{u}}{p_{1}}\right)^{m u}\left(1+\frac{L_{d}}{p_{2}}\right)^{m d}\left(\frac{p_{2}}{p_{1}}\right)^{m p}
$$

in which $b, m, n, m u, m d$, and $m p$ are empirical coefficients that should be determined experimentally. Employing the experimental data listed in Table 2. Di Stefano et al. (2016a) proposed the following stage-discharge curve:

$$
\frac{h}{p_{1}}=1.393\left(\frac{k_{s}}{p_{1}}\right)^{0.947}\left(\frac{L_{w}}{p_{1}}\right)^{0.0167}\left(1+\frac{L_{u}}{p_{1}}\right)^{-0.0716}\left(1+\frac{L_{d}}{p_{2}}\right)^{0.028}\left(\frac{p_{2}}{p_{1}}\right)^{-0.097}
$$

Comparing with the experimental data, the mean absolute relative errors associated with Eq. (28) is shown in Table 3.

As a conclusion Eq. (28) can be used accurately for different kinds of weirs including finite-crested weirs, broad-crested weir with positive or negative crest slope, broad crested weir with upstream, downstream, or both upstream and downstream crest ramps, and, triangular weir with upstream or downstream ramp. Note that, the relative errors of $96 \%$ of the data points were limited within the range of $\pm 10 \%$.

\section{The effect of the approach channel on the head- discharge relationship}

The ratio of the weir width $b$ to the approach channel width $B$ would also affect the head-discharge curve of the rectangular weirs (Gharahjieh et al., 2015). Using the smaller weir width, it would be possible to measure very low discharges. In this regard, Aydin et al. (2002) and Aydin et al. (2006) proposed the design of the slit weir, which is a narrow, vertical, rectangular opening with sharp edges to measure the discharges of less than $0.005 \mathrm{~m}^{3} / \mathrm{s}$.

The stage-discharge relationship for a rectangular weir having a weir width $b$ and a weir height $p$ can be expressed by the following functional relationship (Bijankhan et al., 2016, unpublished data):

$$
\Phi(h, Q, B, p, b, g, \mu, \rho, \sigma)=0
$$

Using the $\Pi$-Theorem of dimensional analysis and neglecting the effects of the Reynolds and Weber numbers, the following functional relationship can be deduced:

$$
f\left(\frac{k_{s}}{p}, \frac{h}{p}, \frac{b}{B}\right)=0
$$

For a given $b / B$ value Eq. (30) assumes the form of Eq. (6). According to the ISS condition, the coefficient $m$ should be a numerical constant and therefore it is independent of $b / B$.

Table 1. The experimental data range of the experimental data of Bijankhan et al. (2015).

\begin{tabular}{cccccc}
\hline p (cm) & Lc (cm) & h $(\mathrm{cm})$ & $\mathbf{Q}(\mathrm{l} / \mathrm{s})$ & Lc/p & h/Lc \\
10 & 0.2 & $1.24-7.17$ & $1.91-19.26$ & 0.02 & $0.061-29.98$ \\
& 5 & & & 0.5 & \\
& 10 & & & 1 & \\
& 15 & & & 1.5 & \\
& 20 & & & 2 & \\
& 30 & & & 3 & \\
20 & 2.5 & $1.26-7.07$ & $2-17.62$ & 0.125 & $0.063-2.232$ \\
& 5 & & & 0.25 & \\
& 15 & & & 0.75 & \\
& 20 & & & 1 & \\
\hline
\end{tabular}


However, in order to calibrate Eq. (6) with the experimental data corresponding to different $b / B$ values the coefficient $a$ should depend on $b / B$.

Employing the experimental data of Gharahjeh et al. (2015), the pairs $\left(k_{s} / p, h / p\right)$ were plotted in Figure 2 for different values of $b / B$. The figure indicates clearly that the coefficient $m$ can be set equal to one, while the coefficient $a$ depends on $b / B$.

The experimentally obtained $a$-values were then plotted versus $b / B$ (Figure 3). As indicated in this figure, using Eq.(7) it would be possible to continuously predict $a$-values from slit weirs $(b / B<0.25)$ to partially rectangular weirs $(b / B>0.25)$. A regression analysis indicated that the following model can be used effectively to accurately determine $a$-values:

$$
a=0.5374(1.416)^{b / B}\left(\frac{b}{B}\right)^{0.5548}
$$

Considering the head-discharge formula as Eq. (6) with $m=1$ and $a$-values calculated by Eq. (31), for each $b / B$ value the average of the absolute relative errors were calculated and resulted almost less than about $5 \%$ for both slit and partially contracted rectangular weirs.

\section{The effect of the obliquity of the rectangular weir}

According to Gentilini (1940) and Borghei et al. (2003) the stage-discharge relationship is affected by the angle $\beta$ between the weir crest and the direction normal to the flow motion. The experimental runs by Borghei et al. (2003) were carried out in a rectangular concrete channel $0.52 \mathrm{~m}$ wide and $0.8 \mathrm{~m}$ height. The length of the channel was equal to $6.6 \mathrm{~m}$. Standard sharp-crested weirs of plexiglass with a height $p$ ranging from 0.46 to $0.51 \mathrm{~m}$ were used. The weirs were placed inside the channel using eight different values of the angle $\beta\left(0,30^{\circ}, 45^{\circ}, 50^{\circ}, 54^{\circ}, 61^{\circ}\right.$ and $\left.64^{\circ}\right)$. Water depth was measured using piezometer taps installed to the side of the channel ( $1 \mathrm{~m}$ upstream of the weir) and this was checked by a point gauge with an accuracy up to $0.1 \mathrm{~mm}$. The discharge used in the

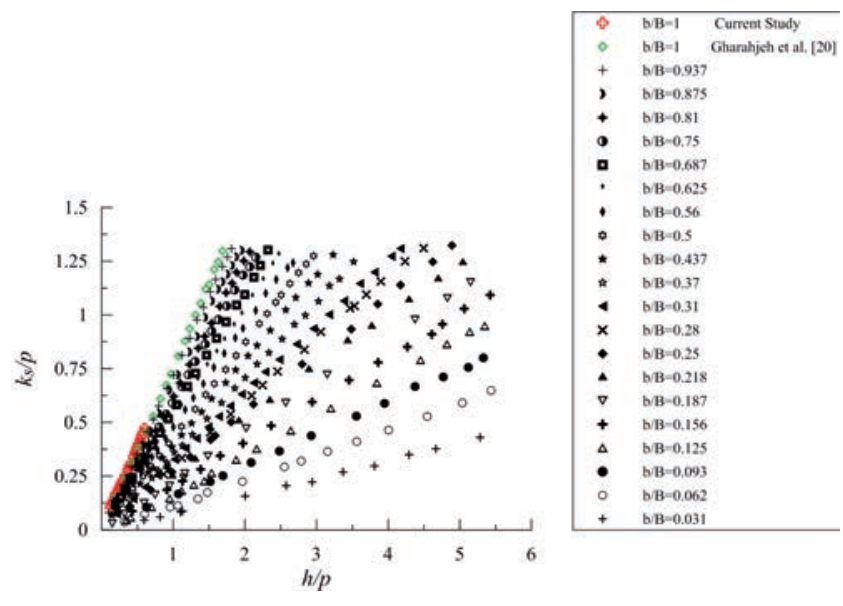

Figure 2. $k_{s} / \mathrm{p}$ versus $h / p$ for different values of $b / B$.

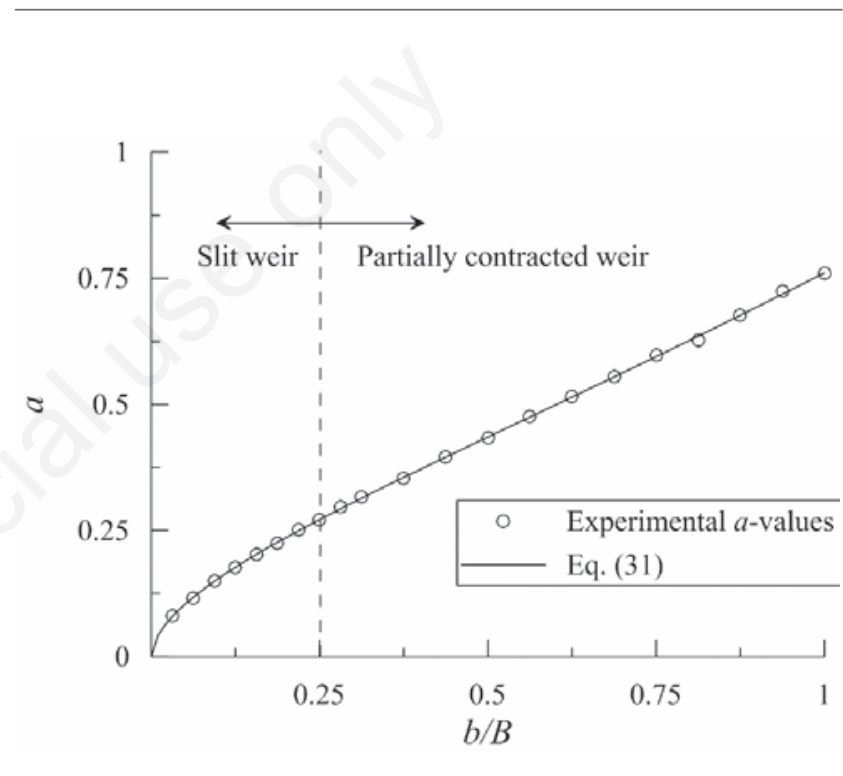

Figure 3. Coefficient a versus $b / B$.

Table 2. Summary of the experimental data used for calibrating Eq. (27) reported by Di Stefano et al. (2016a).

\begin{tabular}{|c|c|c|c|c|c|}
\hline Investigator & $h / p_{1}$ & $p_{2} / p_{1}$ & $\begin{array}{c}\text { Upstream slope, } \\
\alpha \text { (rad) }\end{array}$ & $\begin{array}{c}\text { Downstream } \\
\text { slope, } \beta \text { (rad) }\end{array}$ & $L_{w}(\mathrm{~m})$ \\
\hline $\begin{array}{l}\text { Bazin (from Horton, 1907) } \\
\text { Tests }(86,89,113-115, \\
125136-141,145,147,149-151, \\
153,154,156,158-161,163-165,176,178)\end{array}$ & $0.073-0.89$ & 1 & $0.46-1.57$ & $0.16-1.57$ & $0.002-2$ \\
\hline $\begin{array}{l}\text { United States Deep Waterways } \\
\text { (from Horton, 1907) } \\
\text { Series } 1,2,7,8,16,17,18\end{array}$ & $0.07-3.2$ & $1-3.05$ & $0.28-0.93$ & $0.46-1.57$ & $0.1-2.13$ \\
\hline USGS (from Horton, 1907) & $0.048-0.46$ & 1.31 & 1.57 & 1.57 & 4.87 \\
\hline $\begin{array}{l}\text { Morphy (from Horton, 1907) } \\
\text { Tests cl and c2 }\end{array}$ & $0.24-3.6$ & 1.097 & 1.57 & 1.57 & $1.8-2.3$ \\
\hline Woodburn (1932) & $0.26-0.72$ & 0.98 & 1.57 & 1.57 & 3.66 \\
\hline Tison (1950) & $0.15-0.55$ & 1 & 1.57 & 1.57 & Sharp-crested* \\
\hline Hager and Schwalt (1994) & $0.07-0.5$ & 1 & 1.57 & 1.57 & 0.5 \\
\hline Sisman (2009) & $0.22-1.22$ & 1 & 1.57 & 1.57 & Sharp-crested* \\
\hline Bagheri and Heidarpour (2010) & $0.31-0.94$ & 1 & 1.57 & 1.57 & Sharp-crested* \\
\hline Kumar et al. (2011) & $0.24-0.72$ & 1 & 1.57 & 1.57 & Sharp-crested* \\
\hline
\end{tabular}

USGS, United States Geological Survey. *For all sharp-crested weirs $L_{w}$ was considered to be equal to $0.002 \mathrm{~m}$. 
tests was ranging from 8.8 to $36.481 \mathrm{~s}^{-1}$. The measured pairs water depth $h$-discharge $Q$ are listed, for each investigated weir, in a table from the paper by Borghei et al. (2003).

The analysis showed (Ferro, 2012) that the exponent $m$ of the stage discharge relationship (9) can be set equal to 1 and the coefficient $a$ varies with the angle $\beta$ according to following relationship:

$$
a=0.5887+0.4302 \sin \beta-0.3868(\sin \beta)^{2}
$$

\section{The effect of the inclination of the rectangular weir (pivot weir)}

The inclined rectangular weir, called also as pivot weir (Figure 4) can be used to increase the weir capacity (Prakash et al., 2011).

According to Di Stefano et al. (2016b), for a sharp-crested inclined weir (pivot weir) the stage discharge relationship can be expressed by the following functional relationship:

$\Phi(Q, h, p, b, B, \theta, g, \mu, \rho, \sigma)=0$

where $\Phi$ is a functional symbol. According to the $\Pi$-Theorem, if the effects of the Reynolds number and the Weber number can be considered negligible, Equation (33) can be expressed in the following dimensionless form:

$$
\frac{k_{s}}{p}=\omega\left(\frac{h}{p}, \frac{b}{B}, \sin \theta\right)
$$

where $\omega$ is a functional symbol. For given $b / B$ and $\theta$ values Eq. (34) assumes the form of Eq. (6).

For calibrating Eq. (6) all measurements listed in the report of Wahlin and Reploge (1994) are available. In particular for the data of the experimental tests carried out by US Bureau of Reclamation (USBR) and using the Armtec and USWCL gates' data points, the effect of the gate width ratio, i.e., contracted $(b / B<1)$ and noncontracted $(b / B=1)$, can be distinguished. Moreover, taking into account that some tests were carried out using the values of the ratio $h / p<1$ and other tests (USBR data) using $h / p$ greater than unity, the effect of $h / p$ can also be studied experimentally.

For contracted $(b / B=0.51,0.57$ and 0.84$)$ and non-contracted runs which are also characterised by $h / p$ values less than 1 and different values of $\theta$ angle $\left(24^{\circ}-71.57^{\circ}\right)$, Di Stefano et al. (2016b) showed that for $h / p<1$ a single stage-discharge relationship of Eq. (6) can be used with $a=0.7744$ and $m=1$. In other words, for $h / p<1$ the stage-discharge relationship is independent of both the contraction ratio $b / B$ and the $\theta$ angle.

For non-contracted runs which are also characterised by $h / p$ values greater than 1 and different values of $\theta$ angle $\left(45^{\circ}-71.57^{\circ}\right)$, Di Stefano et al. (2016b) showed a single stage-discharge relationship of Eq. (6) can be used with $a=0.8675$ and $m=1$. In other words, for $h / p>1$ the stage-discharge relationship of non-contracted pivot weirs is independent of the $\theta$ angle.

Nikou et al. (2016) carried out some experiments for $h / R(R=$ $p / \sin \theta$ ) ranging from 0.186 to 0.535 and for three values of the contraction ratio $(0.4,0.6$ and 0.8$)$.

Taking into account that for the experimental data by Nikou et al. (2016) $h / R$ values and the used $\theta$ angles give always values of the $h / p$ ratio less than 1 , the analysis developed by Di Stefano et al. (2016b) confirmed the conclusion, obtained by Wahlin and Reploge's (1994) data, that the stage-discharge relationship for $h / p$ $<1$ is quasi-independent of $\theta$ angle. This analysis also demonstrated that the stage-discharge relationship is independent of the contraction ratio.

In conclusion, the theoretically deduced stage-discharge relationship can be applied and the following equations for estimating the coefficient $a$ and $m$ of Eq. (6) were deduced:

$$
\begin{aligned}
& a=0.7732-2 \cdot 10^{-5} \theta^{2}-0.0003 \theta \\
& m=0.9980-3 \cdot 10^{-5} \theta^{2}+0.0005 \theta
\end{aligned}
$$

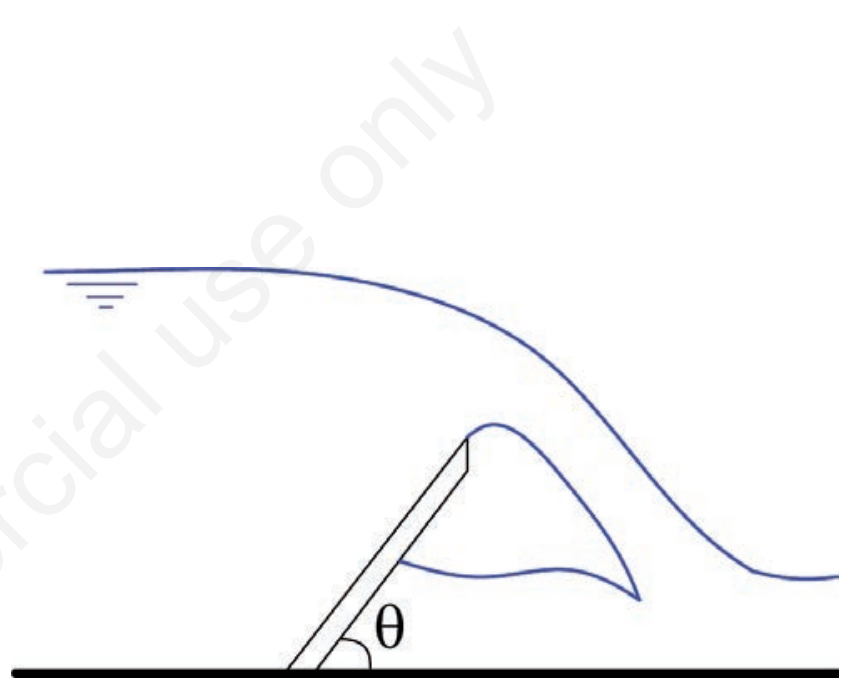

Figure 4. Schematic view of the flow over the inclined rectangular weir (pivot weir).

Table 3. Mean absolute relative errors associated with Eq. (28) reported by Di Stefano et al. (2016b).

\begin{tabular}{lc} 
Weir type & Mean absolute relative error (\%) \\
FCW-Long-crested & $7 \%$ \\
FCW-broad-crested & $10.8 \%$ \\
\hline FCW-Short-crested & $8.6 \%$ \\
FCW-Sharp-crested & $5.4 \%$ \\
\hline TW-DR & $5.5 \%$ \\
TW-UR & $3.3 \%$ \\
\hline TW-UDR & $3.9 \%$ \\
BCW-DR & $8.3 \%$ \\
\hline BCW-UR & $6 \%$ \\
BCW-UDR & $5.6 \%$ \\
\hline BCW-PS & $4.1 \%$ \\
BCW-NS & $13 \%$ \\
\hline
\end{tabular}

FCW, finite crested weirs; TW-DR, triangular weir with a downstream ramp; TW-UR, triangular weir with an upstream ramp; TW-UDR, triangular weir with an upstream and downstream ramp; BCW-DR, broad crested weir with a downstream crest ramp; BCW-UR, broad crested weir with an upstream crest ramp; BCW-UDR, broad crested weir with both upstream and downstream crest ramp; BCW-PS, broad crested weir with a positive crest slope; BCW-NS, broad crested weir with a negative crest slope. 


\section{Triangular weirs}

For a triangular sharp-crested weir having an angle of $90^{\circ}$, named Thomson weir, the stage-discharge equation assumes the following expression:

$Q=\frac{8}{15} C_{d} \sqrt{2 g} h^{5 / 2}$

in which the discharge coefficient assumes the value 0.61 when the approach flow velocity is negligible.

For a Thomson weir installed in a channel having a width $L$, from Eq. (36) we obtain:

$$
\frac{Q^{2}}{L^{2} g}=\left(\frac{128}{225}\right) C_{d}^{2} \frac{h^{5}}{L^{2}}
$$

From Eq. (37) calculating the power $1 / 3$ of both members and dividing for the weir height $p$, Eq. (37) takes the following form:

$\frac{k_{s}}{p}=\left(\frac{128}{225}\right)^{1 / 3} C_{d}^{2 / 3} \frac{h^{5 / 3}}{L^{2 / 3} p} \frac{p^{2 / 3}}{p^{2 / 3}}$

Eq. (38) can be rewritten in the following form:

$$
\left(\frac{k_{s}}{p}\right)^{3 / 5}=\left(\frac{128}{225}\right)^{1 / 5} C_{d}^{2 / 5} \frac{h}{p}\left(\frac{p}{L}\right)^{2 / 5}
$$

Finally, Eq. (39) can be simply rewritten as follows:

$$
\frac{k_{s}}{p}=\left[\left(\frac{128}{225}\right)^{1 / 3} C_{d}^{2 / 3}\left(\frac{p}{L}\right)^{2 / 3}\right]\left(\frac{h}{p}\right)^{5 / 3}
$$

Therefore for a Thomson weir the stage-discharge relationship (6) can be applied with $m=5 / 3$ and $a$ estimated by the following relationship:

$$
a=\left(\frac{128}{225}\right)^{1 / 3} C_{d}^{2 / 3}\left(\frac{p}{L}\right)^{2 / 3}=0.595\left(\frac{P}{L}\right)^{2 / 3}
$$

A sharp-crested weir with a symmetrical triangular section and vertex angle $\theta$ is characterised by the following stage-discharge equation:

$Q=\frac{8}{15} C_{d} \sqrt{2 g} \tan \left(\frac{\theta}{2}\right) h^{5 / 2}$

which can be rewritten in the following form:

$$
\frac{k_{s}}{p}=\left[\left(\frac{128}{225}\right)^{1 / 3}\left(C_{d} \tan \left(\frac{\theta}{2}\right)\right)^{2 / 3}\left(\frac{p}{L}\right)^{2 / 3}\right]\left(\frac{h}{p}\right)^{5 / 3}
$$

Mehrzad et al. (2016), using the experimental data by BautistaCapetillo et al. (2014) corresponding to a vertex angle $\theta=30,90$ and $135^{\circ}$ and $p=30,34$ and $70 \mathrm{~cm}$ deduced that Eq. (6) can be applied with $m=1$ and $a=0.773$.

\section{V-weirs and W-weirs}

For a triangular in plan sharp-crested weir, named also as labyrinth weirs (Figure 5), the stage-discharge relationship can be expressed by the following functional relationship (Di Stefano and Ferro, 2013):

$\Phi(h, Q, p, L, g, \mu, \rho, \sigma, B)=0$

where $\Phi$ is a functional symbol, $\mu$ is the water viscosity, $\rho$ is the water density and $\sigma$ is the water surface tension. For fixed values of both the crest length of the weir $L$ and the channel width $B$, the angle $\alpha$ between the channel sidewall and the side of triangular in plan weir is also known.

Applying the $\Pi$-theorem ad using as dimensional independent variables $p, g$ and $\rho$, the following functional relationship was deduced (Di Stefano and Ferro, 2013):

$$
f\left(\frac{h}{p}, \frac{k_{s}}{p}, \frac{L}{p}, \operatorname{Re}, W e, \sin \alpha\right)=0
$$

Applying the self-similarity condition and neglecting the effects of the Reynolds number and the Weber number, for given values of the ratio $L / p$ and the sidewall angle $\alpha$ the functional relationship (45) assumes the mathematical shape (6).

The theoretical stage-discharge relationship (6) was calibrated using the measurements carried out by Kumar et al. (2011). These Authors carried out their experimental investigation using a horizontal rectangular concrete channel of length $12 \mathrm{~m}, 0.28 \mathrm{~m}$ wide and $0.41 \mathrm{~m}$ deep. The used triangular plan form weir was fabricated of mild steel plates with sharp edge. The experimental runs were performed for the weirs of sidewall angle $\alpha$ equal to $15^{\circ}, 30^{\circ}$, $45^{\circ}, 60^{\circ}, 75^{\circ}$ and $90^{\circ}$. The weir height $p$ ranged from 0.092 to $0.108 \mathrm{~m}$ determining a ratio $L / p$ ranging from 2.8 to 11.8 . Each run series is characterised by a given values of the ratio $L / p$ and the sidewall angle $\alpha$.

For given values of the ratio $L / p$ and the sidewall angle $\alpha$, using the six experimental series of Kumar et al. (2011) the numerical constants of the stage-discharge relationship (6) were estimated. Taking into account that Eq. (6) is applicable for fixed values of the ratio

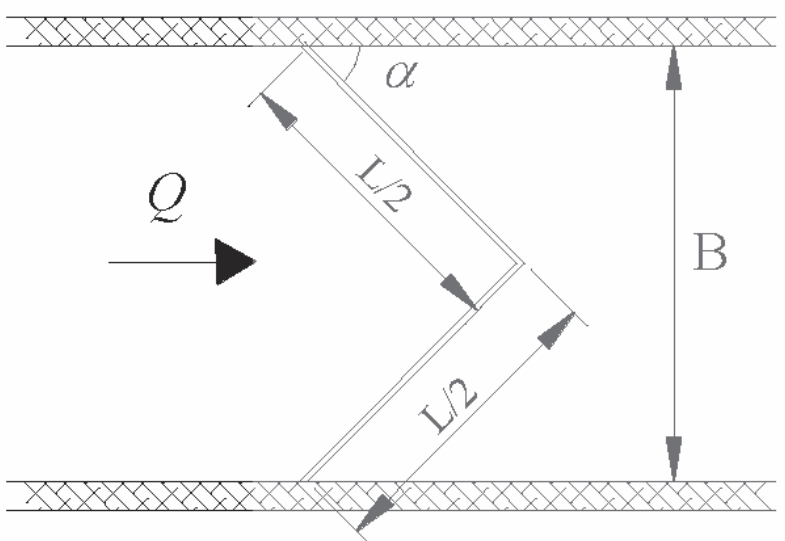

Figure 5. Scheme of the triangular in plan sharp-crested weir. 
between the crest length of the weir and its height and of the sidewall angle $\alpha$ the constants $a$ and $m$ were correlated to $L / p$ and $\alpha$ (radians) according to the following relationships (Di Stefano and Ferro, 2013):

$$
\begin{aligned}
& a=\frac{2.3987}{\left(\frac{L}{p}\right) \alpha^{0.703}} \\
& m=\frac{3.1364}{\left(\frac{L}{p}\right) \alpha^{0.742}}
\end{aligned}
$$

For the W-weirs the theoretical stage-discharge Eq. (6) was calibrated using the measurements carried out by Ferro (2012) (Carollo et al., 2008, 2011). The tests were carried out using a rectangular flume located at the Dipartimento di Ingegneria $e$ Tecnologie Agro-Forestali of the University of Palermo. The flume was $4.90 \mathrm{~m}$ long, 0.304 wide and $0.24 \mathrm{~m}$ deep. The flume was connected to a hydraulic circuit allowing for discharge recirculation. The walls and bed of flume were made of glass. Discharge was measured by an electromagnetic flow meter characterised by a maximum error equal to $0.2 \%$ of the measured value. Three sharp crested W-shaped weirs (Figure 6), made of sheet steel, with four equal sides, having a thickness equal to $2 \mathrm{~mm}$ and an height $p$ equal to $0.1 \mathrm{~m}$ were used. Two weirs were located in the flume using a sidewall angle $\alpha$ equal to $30^{\circ}, 45^{\circ}$ and $135^{\circ}$. For each experimental run, the discharge $Q$ and the water depth $h$ were measured. The water depth was measured by a standard point gauge (accuracy of $0.1 \mathrm{~mm}$ ) at a flume section located $0.4 \mathrm{~m}$ upstream of the weir, sufficient for neglecting the effect of the streamline curvature just upstream of the weir. The experimental runs were carried out using discharge values ranging from 1.4 to $8.81 \mathrm{~s}^{-1}$ and water depth ranging from 1.18 to $5.36 \mathrm{~cm}$.
Three broad crested W-shaped weirs, made of wood with four equal sides, having a thickness equal to $4 \mathrm{~cm}$ and height $p$ ranging from 10.14 to $10.21 \mathrm{~cm}$, were used. For these broad weirs $\alpha$ values were $30^{\circ}, 45^{\circ}$ and $60^{\circ}$.

For the sharp crested $\mathrm{W}$-weir the analysis showed that the exponent $m$ can be set equal to 1 while the coefficient $a$ depends on the $\alpha$ angle according to the following relationship (Carollo et al., 2011):

$a=0.6439(\sin \alpha)^{0.3443}$

For the broad crested W-weir the exponent $m$ can be also set equal to 1 and the coefficient $b$ depends on the $\alpha$ angle according to the following relationship (Carollo et al., 2011):

$a=0.7039(\sin \alpha)^{0.5605}$

\section{Parabolic weirs}

For the parabolic weirs the measurements carried out by Igathinathane et al. (2007) were available. The experimental runs were carried out in a flume $10 \mathrm{~m}$ long and having a cross-sectional dimension of $0.3 \mathrm{~m}$ width and $0.63 \mathrm{~m}$ depth. Weir dimensions were selected to conform the hydraulic flume dimensions and the equation of the parabola profile used to fabricate the weirs was the following:

$$
y=\frac{x^{2}}{H\left(\tan \frac{\theta}{2}\right)^{2}}
$$
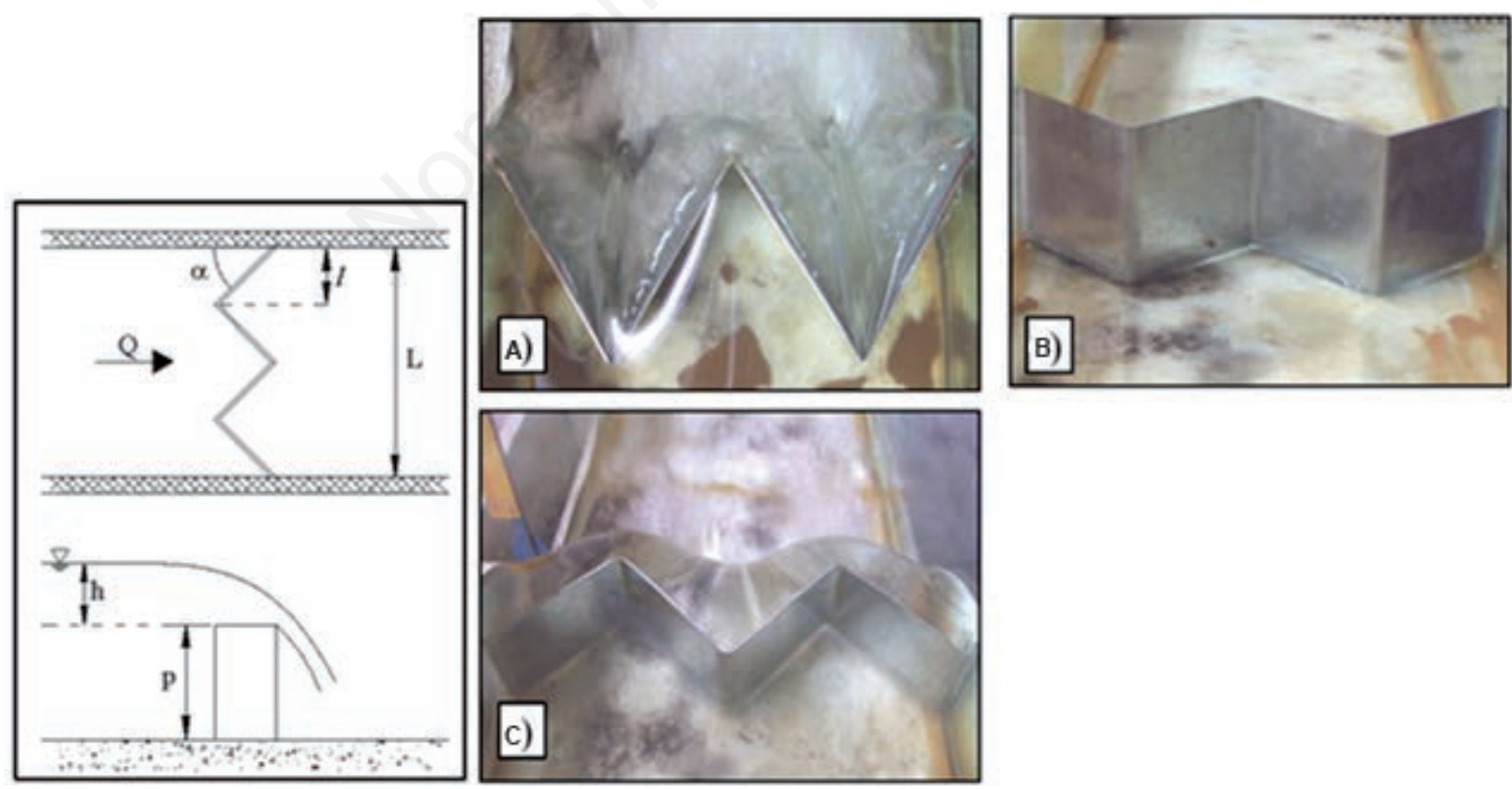

Figure 6. A-C) Weirs used in the investigation by Ferro (2012). 
where $x$ and $y$ are weir profile horizontal and vertical coordinates, $H$ is total length of weir profile, $L$ is the maximum width of the weir profile and $\theta$ is weir angle $(L=2 H \tan \theta)$. The experimental investigation was carried out for four values of weir angle $\left(30^{\circ}\right.$, $45^{\circ}, 60^{\circ}$ and $\left.90^{\circ}\right)$ and three values of the weir height $p(0.139$, 0.124 and $0.186 \mathrm{~m}$ ). Discharge values ranging from 0.65 to $9.81 \mathrm{~s}^{-1}$ and water depth ranging from 3.6 to $19.3 \mathrm{~cm}$ were used. The measured pairs water depth $h$-discharge $Q$ are listed, for each investigated weir, in a table from the paper of Igathinathane et al. (2007).

For the parabolic weirs the weir width, useful for calculating the water depth $k_{s}$, was set equal to the maximum width $L$ of the parabolic weir.

The comparison between Eq. (6) with $m=1.2658$ and the data pairs of Igathinathane et al. (2007) showed a good agreement of the theoretical stage-discharge equations and the available measurements. The analysis also demonstrated that $a$ depends on the ratio $H / p$ according to the following equation (Ferro, 2012):

$a=0.6158\left(\frac{H}{p}\right)^{-0.2742}$

\section{Circular and elliptical weirs}

Employing the fundamental weir flow formula (Ramponi, 1936; Ferroglio, 1938; Balachandar et al., 1991) and integrating the theoretical velocity profile would result in complex equations that should be solved numerically (Vatankhah, 2010; Ghobadian and Meratifashi, 2012).

Staus $(1930,1931,1937,1939)$ was the true promotor of the circular weir and he derived a theory of the circular weir and computed a table of values involving elliptical integrals. He proposed the following stage-discharge formula:

$\frac{Q_{t}}{g^{1 / 2} D^{5 / 2}}=\frac{4}{15} \sqrt{2}\left[2\left(1-\frac{h}{D}+\frac{h^{2}}{D^{2}}\right) E_{1}-\left(2-3 \frac{h}{D}+\frac{h^{2}}{D^{2}}\right) E_{2}\right]$

in which $Q_{t}$ is the theoretical discharge which does not take into account the effect of the approach velocity and head losses, and $E_{1}$ and $E_{2}$ are the complete elliptic integral of the first and second types, respectively, which depend on the ratio $h / D$.

Staus $(1930,1931,1937,1939)$ investigated 5 weirs of the diameters ranging from $0.198 \mathrm{~m}$ to $0.3048 \mathrm{~m}$ and proposed the following empirical formula for calculating the discharge coefficient $C_{d}$ of a circular weir:

$$
C_{d}=0.555+\frac{1}{110 \frac{h}{D}}+0.041 \frac{h}{D}
$$

The stage-discharge relationship $h-Q$ is obtained by replacing into Eq.(52) $Q_{t}$ with $Q$ and multiplying the second term of the equation by $C_{d}$.

The Equation (52) obtained by Staus (1930, 1931, 1937, 1939) can be generalised for an elliptical weir (Sommerfeld and Stallybrass, 1996) in which $a$ and $b$ are the semi-major and semiminor axes, respectively:
$\frac{Q_{t}}{g^{1 / 2} a b^{3 / 2}}=\frac{32}{15}\left[2\left(1-\frac{h}{2 b}+\frac{h^{2}}{(2 b)^{2}}\right) E_{1}-\left(2-3 \frac{h}{2 b}+\frac{h^{2}}{(2 b)^{2}}\right) E_{2}\right]$

Dimensional analysis provides however simple and accurate enough formulas for calibrating the circular weir. The functional relationship of the flow over a circular weir having a height $p$, a maximum weir width equal to the diameter $D$, installed in a channel having a width $B$, takes the following form:

$\Phi(h, Q, B, p, D, g, \mu, \rho, \sigma)=0$

Neglecting the influence of the Reynolds and Weber numbers, the stage-discharge equation of the circular weir can be expressed by the following functional relationship:

$f\left(\frac{h}{D}, \frac{Q}{g^{1 / 2} D^{5 / 2}}, \frac{B}{D}, \frac{p}{D}\right)=0$

According to Jorissen (1943), the effect of the weir height is negligible if the ratio $p / D$ is greater than 0.7 Also he indicated that, for $B / D>2$ the effect of the approaching channel width can also be neglected. Consequently for $p / D>0.7$ and $B / D>2$ the stage-discharge relationship, Eq. (56), takes the following form:

$f\left(\frac{h}{D}, \frac{Q}{g^{1 / 2} D^{5 / 2}}\right)=0$

The mathematical shape of Eq. (57) can be studied using the incomplete self-similarity concept. For a given diameter $D$, when the upstream water depth tends to zero then the discharge $Q \rightarrow 0$, while when $h \rightarrow+\infty$ then $Q \rightarrow+\infty$. Consequently the ISS conditions occurs and Eq. (57) can be written as:

$$
\frac{h}{D}=a\left(\frac{Q}{g^{1 / 2} D^{5 / 2}}\right)^{n}
$$

The coefficients $a$ and $n$ are empirical coefficients that should be determined experimentally. In this regard, experimental data points of Greve (1932) Cone [reported in Stevens (1957)], Thijsse [reported in Stevens (1957)], and Dodge (1935, unpublished data) were used to calibrate Eq. (58).

Plotting $h / D$ versus $Q /\left(g^{1 / 2} D^{5 / 2}\right)$ it was observed that the experimental data associated with different weir diameters would collapse on a single curve. Consequently, the stage-discharge curve of the employed experimental data can be considered to be independent of the ratio $B / D$. Using the power law regression analysis the coefficients $a$ and $n$ and the mean absolute relative errors (MARE), were calculated and listed in Table 4 . It can be observed that MARE is ranged from $0.92 \%$ to $4.74 \%$. It is however recommended to recalibrate Eq. (58) for any new data sets.

\section{Practical outcomes, limitation and research needs}

Increasing the weir capacity is always important for the engineers. Actually, the more discharge capacity would result in the less costs of the upstream protection. Consequently, any effort to 
increase the weir capacity would be of great practical importance. In this regard labyrinth weirs has attracted the attention of the investigators. Piano key weirs are also an improved structure of the labyrinth weirs, which can be used effectively to increase the weir capacity (Riberio et al., 2012). Note that, both labyrinth and piano key weirs are designed based on increasing the effective weir length. Prakash et al. (2011) indicated that the inclined weir type could also be used to increase the weir capacity. Recently, Nikou et al. (2016) investigated the stage-discharge curves of free and submerged inclined rectangular weirs called as pivot weir. They reported that the stage-discharge formula should be considered as a function of the weir inclination angle.

Employing the experimental data of Wahlin and Replogle (1994), and applying the dimensional analysis, $k_{s} / p$ was plotted versus $h / p$ in Figure 7 for different values of the gate inclinations ranging from $20^{\circ}$ to $70^{\circ}$. According to the figure it was revealed that the gate inclination would affect the head-discharge curve marginally (Di Stefano et al., 2016b). This conclusion is however in contradiction with the results of the investigation of Prakash et al. (2011) that reports a significant influence of the gate inclination on the head-discharge formula. Consequently in this case the researchers are not in an agreement and further theoretical and experimental studies are required for a general conclusion.

Usually weirs are designed to work under free flow conditions. However, in practice they can also be submerged due to the tailwater effects. In such a case the tailwater depth should also appear in the functional relationship and therefore the free flow head-discharge formula is useless. There are however very limited studies to investigate the effect of the submergence on the stage-discharge relationship. Consequently further experimental and theoretical studies are suggested to illustrate better the effect of the tailwater depth on the hydraulics of the flow over submerged weirs.

Table 4. The empirical coefficients and mean absolute relative errors of Eq. (58) for different experimental data.

\begin{tabular}{lccc} 
Data set & $a$ & $n$ & Mean absolute relative error (\%) \\
Dodge & 1.549 & 0.591 & 1.58 \\
Cone & 1.527 & 0.548 & 4.74 \\
\hline Greve & 1.559 & 0.568 & 2.03 \\
Thijsse & 1.263 & 0.499 & 0.92 \\
\hline
\end{tabular}
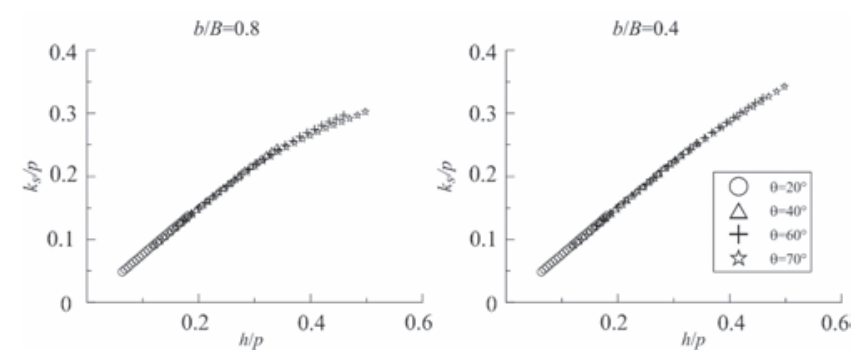

Figure 7. $k_{s} / p$ versus $h / p$ for different values of the gate inclinations.

\section{Conclusions}

In this study it is indicated that the dimensional analysis, the Buckingham's theorem and incomplete self-similarity concepts can be used to find the overall trend of the rating curves of different weir types. Rectangular, triangular, labyrinth, parabolic, circular, elliptical and W-weirs were considered and the calibrated stage-discharge formulas are presented. For the rectangular weirs, the definition of the complex crest shape is considered. Then the associated general stage-discharge formula is developed which is applicable for long-, broad-, short- and sharp-crested, weirs as well as different kinds of broad crested weirs, i.e., with/without upstream and downstream crest ramps. Furthermore, the effects of the approach channel width and weir obliquity are discussed in detail. The stage-discharge relationship of the inclined rectangular weir, named as pivot weir, was considered in this review paper. In conclusion, the incomplete self-similarity concept resulted in a power law expression for the weir flow procedure, which can be used effectively for accurate water measuring over different kinds of weirs.

\section{References}

Aydin I., Altan-Sakarya A., Ger A. 2006. Performance of slit weir. J. Hydr. Eng. 132:987-9.

Aydin I., Burcu Altan-Sakarya A., Sisman C. 2011. Discharge formula for rectangular sharp-crested weirs. Flow Measure. Instr. 22:144-51.

Aydin I., Ger A., Hincal O. 2002. Measurement of small discharges in open channels by slit weir. J. Hydr. Eng. 128: 234-7.

Azimi A., Rajaratnam N. 2009. Discharge characteristics of weirs of finite crest length. J. Hydr. Eng. ASCE 135:1081-5.

Azimi A., Rajaratnam N., Zhu D. 2013a. Discharge characteristics of weirs of finite crest length with upstream and downstream ramps. J. Irrig. Drain. Eng. 139:75-83.

Azimi A., Rajaratnam N., Zhu D. 2013b. Discussion of "New theoretical solution of the stage-discharge relationship for sharpcrested and broad weirs" by V. Ferro. J. Irrig. Drain. Eng. ASCE 139:516-17.

Bagheri S., Heidarpour M. 2010. Flow over rectangular sharpcrested weirs. Irrig. Sci. 28:173-9.

Balachandar R., Sorbo S., Ramamurthy S. 1991. A note on circular sharp-crested weirs. Canad. J. Civil Engine. 18:881-5.

Barenblatt G.I. 1979. Similarity, self-similarity and intermediate asymptotics. Consultants Bureau, New York, NY, USA.

Barenblatt G.I. 1987. Dimensional analysis. Gordon \& Breach, Science Publishers Inc., Amsterdam, The Netherlands.

Bautista-Capetillo C., Roble O., Júnez-Ferreira H., Playán E. 2014. Discharge coefficient analysis for triangular sharp-crested weirs using low-speed photographic technique. J. Irrig. Drain. Engine. ASCE 140:06013005.

Bijankhan M., Di Stefano C., Ferro V., Kouchakzadeh S. 2014. New-stage discharge relationship for weirs of finite crest length. J. Irrig. Drain. Eng. ASCE 140:06013006-1-06013006-8.

Bijankhan M., Di Stefano C., Ferro V., Kouchakzadeh S. 2015. Closure to "New stage-discharge relationship for weirs of finite crest length". J. Irrig. Drain. Eng. ASCE 141:070150111-07015011-3.

Borghei S.M., Vatannia Z., Ghodsian M., Jalili M.R. 2003. Oblique rectangular sharp-crested weir. Proc. ICE Water \& Maritime 
Engineering 156:185-91.

Bos M.G. 1989. Discharge measurement structures. International Institute for Land Reclamation and Improvement (ILRI), Wageningen, The Netherlands.

Carollo F.G., Ferro V., Pampalone V. 2008. Esperienze sull'efflusso di uno sfioratore a profilo W. Quad. Idronomia Montana 28/2:405-20.

Carollo F.G., Ferro V., Pampalone V. 2011. Experimental investigation of the outflow process over a triangular labyrinth-weir. J. Irrig. Drain. Eng. ASCE 138:73-9.

Darvas L.A. 1971. Discussion of performance and design of labyrinth weirs, by Hay and Taylor. Hydr. Engine. ASCE 97:1246-51.

De Martino G., Ragone A. 1984. Effects of viscosity and surface tension on slot weirs flow. J. Hydr. Res. 22:327-41.

Di Stefano C., Ferro V. 2013. A new approach for deducing the stage-discharge relationship of triangular in plan sharp-crested weirs. Flow Measure. Instr. 32:71-5.

Di Stefano C., Ferro V., Bijankhan M. 2016a. Discussion of "Extraction of the flow rate equation under free and submerged flow conditions in pivot weirs with different side contractions by S.R. Nikou, M.J. Monem and K. Safavi”. J. Irrig. Drain. Eng. ASCE [In press].

Di Stefano C., Ferro V., Bijankhan M. 2016b. New theoretical solution of the outflow process for a weir with complex shape. J. Irrig. Drain. Eng. ASCE. 142:04016036-1-9.

Ferro V. 2012. New theoretical solution of the stage-discharge relationship for sharp-crested and broad weirs. J. Irrig. Drain. Eng. ASCE 138:257-65.

Ferro V. 2013. Closure to "New theoretical solution of the stagedischarge relationship for sharp-crested and broad weirs by V. Ferro". J. Irrig. Drain. Eng. ASCE 139:518-20.

Ferroglio L. 1938. Contributo allo studio dello stramazzo circolare. L'Industria LII:214-21.

Gentilini B. 1940. Stramazzi con cresta a pianta obliqua e zigzag. Memorie e Studi del Regio Politecnico di Milano 48:1-12.

Gharahjeh S., Aydin I., Altan-Sakarya A.B. 2015. Weir velocity formulation for sharp-crested rectangular weirs. Flow Measure. Instr. 41:50-6.

Ghobadian R., Meratifashi E. 2012. Modified theoretical stage-discharge relation for circular sharp-crested weirs. J. Water Sci. Engine. 5:26-33.

Greve F.V. 1932. Flow of water through circular, parabolic, and triangular vertical notch weirs. Engine Bull. Purdue Univ. 40:37-60.

Hager W.H., Schwalt M. 1994. Broad-crested weir. J. Irrig. Drainage Eng. ASCE 120:13-26.

Hay N., Taylor G. 1970. Performance and design of labyrinth weirs. J. Irrig. Drainage Eng. ASCE 96:2337-57.

Herschy H. 1999. Hydrometry. Principles and practices. Wiley, New York, NY, USA, pp 55-60.

Horton R.E. 1907. Weir experiments, coefficients, and formulas. Proc. U.S. Geological Survey Water Supply, Government Printing Office, Washington, DC, USA.

Igathinathane C, Srikanth I, Prakash K, Ramesh B, Womac AR. 2007. Development of parabolic weirs for simplified discharge measurement. Biosyst. Eng. 96:111-9.
Jorissen A. 1943. Contribution a l'etude du deversoir circulaire en mince paroi. Rev. Gén. Hydr. 9:9-23.

Kumar S., Ahmad Z., Mansoor T. 2011. A new approach to improve the discharging capacity of sharp-crested triangular plan form weirs. Flow Measure. Instr. 22:175-80.

Mehrzad M., Kouchakzadeh S., Bijankhan M. 2016. Discussion of "Discharge coefficient analysis for triangular sharp-crested weirs using low-speed photographic technique" by BautistaCapetillo C, Roble O, Júnez-Ferreira H, Playán E. J. Irrig. Drainage Eng. ASCE 142:07014066-1-07014066-2.

Nikou N.S.R., Monem M.J., Safavi K. 2016. Extraction of the flow rate equation under free and submerged flow conditions in pivot weirs with different side contractions. J. Irrig. Drainage Eng. ASCE 142:04016025-1-04016025-8.

Prakash M.N.S., Ananthayya M.B., Kovoor G.M. 2011. Inclined rectangular weir-flow modeling. J. Earth Sci. India 4:57-67.

Ramponi F. 1936. Sugli stramazzi di misura circolari. L'Energia Elettrica 13:51-8.

Ranga Raju K.G., Asawa G.L. 1977. Viscosity and surface tension effects on weir flow. J. Hydr. Div. ASCE 103:1227-31.

Rao S.S., Shukla M.J. 1971. Characteristics of flow over weirs of finite crest width. J. Hydr. Div. ASCE 97:1807-16.

Riberio M.L., Bieri M., Boillat J.L., Schleiss A.J., Singhal G., Sharma N. 2012. Discharge capacity of piano key weirs. J. Hydr. Eng. 138:199-203.

Sargison E.J. 1972. The influence of surface tension on weir flow. J. Hydr. Res. 10:431-46.

Sisman H.C. 2009. Experimental investigation on sharp-crested rectangular weirs. MSc Thesis, Middle East University, Ankara, Turkey.

Sommerfeld J.T., Stallybrass M.P. 1996. Flow equations for parabolic and elliptical weirs. J. Environ. Sci. Health A31:905-12.

Staus A. 1930. Zur berechnung kreisrunder überfälle. Wasserkr. u. Wasserwirtsch. 25:122-3.

Staus A. 1931. Der beiwert kreisrunder überfälle. Wasserkr. u. Wasserwirtsch. 26:42-4.

Staus A. 1937. Der kreisüberfälle. Wasserkr. u. Wasserwirtsch. 32:116-9.

Staus A. 1939. Der kreisűberfäll und sein beiwert. Wasserkr. u. Wasserwirtsch. 34:79-83.

Stevens J.C. 1957. Flow through circular weirs. J. Hydr. Div. ASCE 83:1-24.

Taylor G. 1968. The performance of labyrinth weir. Thesis presented to University of Nottingham, England.

Tison L.J. 1950. Le déversoir à seuil épais. La Houille Blanche 4:426-39.

Tullis P., Amanian N., Waldron D. 1995. Design of labyrinth weir spillways. J. Hydr. Eng. 121:247-55.

Vatankhah A.R. 2010. Flow measurement using circular sharp crested weirs. Flow Measure. Instr. 21:118-22.

Wahlin B.T., Replogle J.A. 1994. Flow measurement using an overshot gate. U.S. Department of the Interior Bureau of Reclamation, Denver, CO, USA.

Woodburn J.G. 1932. Tests on broad-crested weirs. Trans. ASCE 96:387-408. 